\title{
A ARBITRAGEM KABEL: UM CASE BRASILEIRO NA FINLÂNDIA
}

\author{
THE KABEL ARBITRATION: A BRAZILIAN CASE IN FINLAND
}

Felipe Dutra Gurgel Cavalcanti”

\begin{abstract}
Resumo: $O$ presente artigo traz alguns dos principais aspectos que envolvem o instituto da arbitragem na República da Finlândia, tendo como base o contido na Lei 1992/967 daquele país (Finnish Arbitration Act - FAA), e buscando o cotejo com os dispositivos regentes da matéria no direito brasileiro. Como exemplo prático, são apresentadas as linhas gerais da arbitragem Kabel, realizada na Finlândia tendo empresa brasileira como parte.
\end{abstract}

Palavras-chave: Arbitragem. Finnish Arbitration Act. Lei n.ำ 9.307/1996. Case Kabel.

Abstract: The present article brings some of the main aspects related to arbitration in the Republic of Finland, based on the 1992/967 Act (Finnish Arbitration Act - FAA), and compares them with Brazil's legal provisions on the matter. As a practical example, a general outline of the case Kabel, held in Finland with a Brazilian company as a party, is presented.

Key-words: Arbitration. Finnish Arbitration Act. Lei n.ำ 9.307/1996. Case Kabel.

\section{INTRODUÇÃO}

A utilização do instituto da arbitragem como modo de resolução de controvérsias tem se tornado crescentemente popular na Finlândia nos últimos anos. Rota de comércio e tradicional player do sistema internacional de trocas, o país é membro da União Europeia desde 1995, e sede de multinacionais do porte de Nokia e Kone. Em geral, as empresas finlandesas recorrem à arbitragem porque desejam solução rápida para litígios de natureza frequentemente complexa, cujo deslinde demandaria maior tempo perante a jurisdição regular. Sintoma disso é que a inclusão de cláusulas de arbitragem nos contratos já é regra, não exceção.

"Graduado em Direito (2000) e em Comunicação Social/Jornalismo (2005), ambas pela Universidade Federal de Pernambuco (UFPE). Atualmente é Procurador Federal lotado em Brasília/DF, com atuação perante a Coordenação-Geral Agrária (CGA) da Procuradoria Federal Especializada do INCRA/SEDE - PFE/INCRA. Email: fdgc2002@yahoo.com.br. 
$\mathrm{Na}$ Finlândia, o mais importante instituto de arbitragem é o da Câmara Central de Comércio (em finlandês, Keskuskauppakamarı), com sede em Helsinki, e que promove arbitragens em disputas comerciais domésticas ou internacionais, podendo também, sendo o caso, apenas indicar os árbitros da contenda. Em 2009, esse instituto recebeu 65 pedidos de arbitragem ${ }^{1}$, sendo mais de um terço deles relativos a disputas internacionais, as quais foram decididas à luz do mesmo diploma legal finlandês que disciplina os litígios domésticos.

Promulgada em 23 de outubro de 1992, a Lei de Arbitragem da República da Finlândia (ou Finnish Arbitration $A c t^{2}$, doravante referido como FAA) entrou em vigor no dia $1^{\circ}$ de dezembro do mesmo ano. Sua divisão em duas partes (a primeira votada à arbitragem em território finlandês, a segunda dedicada aos efeitos que nesse território são gerados por convenção arbitral havida no estrangeiro) deveu-se à intenção do legislador de deixar claro seu campo de aplicação, uma vez que o $F A A$ adota o princípio segundo o qual a arbitragem é regida pela lei do lugar em que celebrada.

$\mathrm{Na}$ primeira parte do artigo, cuidaremos de expor os principais aspectos da arbitragem na Finlândia, notadamente aqueles contidos no $F A A$, comparandoos, quando for o caso, com seus similares no direito brasileiro.

$\mathrm{Na}$ segunda parte, apresentaremos as linhas gerais do case Kabel, arbitragem realizada em Helsinki entre 2006 e 2008 envolvendo empresas finlandesa e brasileira em matéria de direito societário. O caso é particularmente útil para ilustrar o exposto na primeira parte do artigo porque seu procedimento foi regido pelo $F A A$, ao tempo em que seu mérito foi decidido à luz do direito material brasileiro.

\section{ASPECTOS DA ARBITRAGEM NA FINLÂNDIA}

\subsection{A Convenção Arbitral}

A convenção arbitral é regulada pelo $F A A$ em seus artigos 2 a 6 e 41 . Não é feita distinção entre a submissão, que se dá quando a convenção se refere a um litígio já existente - instituto conhecido entre nós como compromisso arbitral -, e a cláusula arbitral, que apenas prevê a convenção caso haja disputa - e que equivale à nossa cláusula compromissória.

Essa diferenciação entre os institutos existe, contudo, em outros diplomas do direito finlandês, notadamente na legislação consumerista e na que rege

\footnotetext{
${ }^{1}$ Finland Central Chamber of Commerce.

${ }^{2}$ A versão da lei de arbitragem finlandesa a que tivemos acesso é uma tradução nãooficial para o Inglês contida em Savola (2004. p. 77-90).
} 
alguns contratos de transporte. Nessas avenças, a cláusula arbitral é considerada inválida ou impassível de ser invocada contra o hipossuficiente. No Brasil, nossa Lei de Arbitragem somente faz menção à eficácia limitada da cláusula compromissória em relação aos contratos de adesão ${ }^{3}$ Por outro lado, uma convenção arbitral instaurada por meio da submissão, mesmo quanto a contratos oriundos de relações de consumo ou de transporte, torna-se válida e vinculante para ambas as partes.

O domínio da arbitragem na Finlândia é significativamente mais amplo que no direito brasileiro. Enquanto nós a limitamos a "litígios relativos a direitos patrimoniais disponíveis", ali ela se estende a qualquer disputa em matéria civil ou comercial que possa ser dirimida por acordo entre as partes ${ }^{5}$. Uma disputa que não possa ser resolvida dessa maneira, por lógica, não é arbitrável. Gustaf Möller (2004, p. 8) enumera, a título de exemplificação, controvérsias envolvendo estado civil, capacidade, divórcio, adoção e guarda como excluídas do domínio da arbitragem no direito finlandês.

Deve ser notado que normas de observância obrigatória e as de ordem pública não interferem na arbitrabilidade de uma disputa, embora, por óbvio, o reconhecimento e a execução do laudo arbitral a elas devam obediência, sob pena de tornar o laudo nulo, e sua execução proibida ${ }^{6}$.

Em particular, são objeto de discussão, quanto à arbitrabilidade, as seguintes matérias:

Os direitos de patente e as marcas registradas são, em larga medida, arbitráveis, e as cláusulas arbitrais são bastante comuns em acordos de licenciamento. Também as causas que envolvam insolvência podem ser arbitradas, desde que a convenção arbitral tenha sido celebrada pelo devedor antes da judicialização da causa. E as meras questões de fato também podem ser objeto de arbitragem, desde que esses fatos possuam uma ligação direta com questões jurídicas (geralmente, de direito civil ou comercial) que possam ser levadas a juízo (p. ex., se determinados bens foram entregues em conformidade com a previsão

${ }^{3}$ Artigo 4ำ § 2º da Lei n. 9.307/1996: "Nos contratos de adesão, a cláusula compromissória só terá eficácia se o aderente tomar a iniciativa de instituir a arbitragem ou concordar, expressamente, com a sua instituição, desde que por escrito em documento anexo ou em negrito, com a assinatura ou visto especialmente para essa cláusula”.

${ }^{4}$ Nos termos do artigo $1^{\circ}$ da Lei n. 9.307/1996.

${ }_{6}^{5}$ FAA, artigo $2^{\circ}$.

${ }^{6} \mathrm{O}$ artigo $2^{\circ}$, $\S 2^{\circ}$ da Lei n. 9.307/1996 prescreve estrita observância das partes à ordem pública e aos bons costumes, desde a escolha das regras de direito que serão aplicadas na arbitragem. 
contratual). Se ausente esse liame, não há de se falar em arbitragem. Por fim, a interpretação de contratos pode ser tarefa delegada a um árbitro, a quem são conferidos, pela lei finlandesa, poderes equiparáveis ao de um juiz para aferir fatos supervenientes que alterem o equilíbrio contratual, como por exemplo variações cambiais excessivas em contratos de longo prazo.

A convenção arbitral deve ser por escrito, sendo verdadeira condição de sua validade. Ela pode ser obtida tanto quando a convenção está contida em um documento formal assinado pelas partes como quando há troca de correspondências, telegramas ou fac-símiles entre as partes contratantes ${ }^{7}$.

A exemplo do que prevê a lei brasileira em seu artigo $4^{\circ}, \S 1^{\circ}{ }^{8}$, na Finlândia é aceita a menção, no texto do contrato, a um documento contendo cláusula arbitral. A convenção arbitral, nessa hipótese, se perfaz quando o contrato é por escrito e a referência é suficiente para caracterizar a cláusula como parte do instrumento 9 .

Todas as pessoas que possuam capacidade para celebrar contrato relativo à matéria submetida a arbitragem também a possuem para celebrar convenção arbitral. Na Finlândia, o Estado e suas agências podem recorrer à arbitragem indistintamente, seja com seus nacionais ou com estrangeiros, sob as mesmas condições aplicáveis a particulares.

Como em qualquer ordenamento jurídico nacional, na Finlândia é recomendável que a cláusula arbitral seja ampla o suficiente para abranger todas as disputas que possam advir de um determinado contrato. A preocupação maior é a de que nenhuma controvérsia contratual seja levada a juízo e a arbitragem simultaneamente, conduzindo a decisões conflitantes. Garantida sua abrangência, a cláusula arbitral dificilmente terá sua eficácia posta em risco em face de eventuais omissões. Por exemplo, o FAA estipula o número de três árbitros no silêncio das partes em deixar expressa na cláusula arbitral a sua quantidade ${ }^{10}$. As partes podem, ainda, determinar qual a legislação aplicável à disputa, ou ainda quais as regras de direito sobre ela incidentes, assim como no direito brasileiro ${ }^{11}$.

Havendo cessão de direitos contratuais em relação a uma das partes contratantes, é garantido à parte original invocar a convenção arbitral em face do cessionário. A recíproca não ocorre sempre: pode haver certas circunstâncias

\footnotetext{
${ }^{7}$ Artigo $3^{\circ}$, $\S 2^{\circ}$ do $F A A$.

${ }^{8}$ Eis o seu teor: "A cláusula compromissória deve ser estipulada por escrito, podendo estar inserta no próprio contrato ou em documento apartado que a ele se refira”.

${ }^{9}$ Artigo $3^{\circ}, \S 3^{\circ}$ do FAA.

${ }^{10}$ Idem, artigo 7ㅇ.

${ }^{11}$ Artigo 2ํㅡㅇ $§ 1^{\circ}$ da Lei n. 9.307/1996.
} 
em que seria desarrazoado permitir que o cessionário invocasse a convenção em face da parte original. Por esse motivo, em cláusulas arbitrais de contratos comerciais, é comum ser expressa a permissão (ou não) concedida à nova parte para fazer uso da convenção arbitral.

Do mesmo modo que sucede com a lei brasileira ${ }^{12}$, na Finlândia a validade de um contrato não afeta a da cláusula arbitral nele contida - princípio entre nós conhecido como da autonomia da cláusula compromissória. Essa concepção é mais ou menos aceita na doutrina finlandesa e nas decisões da Korkein oikeus, a Suprema Corte daquele país.

Em princípio, a convenção arbitral exclui a jurisdição regular. Para isso, entretanto, a parte interessada deve invocá-lo antes do conhecimento da matéria pelo juízo. Se isso não ocorrer, não é dado ao juízo declinar de sua jurisdição por força da convenção arbitral. Mas se ela for tempestivamente invocada, não há discricionariedade do juízo, cabendo quando muito aferir-se a regularidade e validade da convenção. Estando a mesma em ordem, a questão será submetida à arbitragem. Ressalve-se, contudo, que a convenção arbitral não exclui a apreciação, pela jurisdição estatal, de medidas cautelares e protetivas de direitos.

Nunca é demais recordar que as normas de ordem pública e de observância obrigatória só consistem empecilhos à arbitrabilidade de matéria quando o laudo arbitral as infrinja manifestamente, o que dá azo à recusa em executá-lo ou mesmo em reconhecê-lo.

É lícito às partes estipular, como balizamento dos procedimentos da arbitragem, as regras de um determinado instituto, como por exemplo as da UNCITRAL (Comissão das Nações Unidas para o Direito Mercantil Internacional).

Há certas circunstâncias que afastam a possibilidade de se invocar validamente a convenção arbitral, previstas no artigo 60 do $F A A$. São elas:

- Quando uma parte contesta ou recusa pedido de submissão à arbitragem feito pela outra parte;

- Quando uma parte deixa de indicar árbitro tempestivamente; ou

- Quando uma parte não efetua o depósito prévio ou não paga as custas a que fazem jus os árbitros.

$\mathrm{Na}$ ocorrência de qualquer dessas circunstâncias, configura-se verdadeira quebra da convenção arbitral, suficiente para autorizar a parte adversa a levar a questão a juízo, independentemente da existência de convenção.

${ }^{12}$ Artigo 8. da Lei n. 9.307/1996. 


\subsection{O Tribunal Arbitral}

$\mathrm{Na}$ Finlândia, obedece-se ao princípio universal segundo o qual a inércia de uma das partes, em qualquer fase, não frustra o regular andamento do processo arbitral. Uma parte pode, por exemplo, recusar-se a designar seu árbitro. Nesse caso, os artigos 15, 16 e 17 do $F A A$ preveem que o árbitro deverá ser indicado pelo juízo finlandês competente.

O mais comum é que as partes optem pelo número de um ou três árbitros. Neste último caso, ainda que a cláusula arbitral assim o preveja, nada impede que as partes, de comum acordo, modifiquem o número para um árbitro apenas.

$\mathrm{Na}$ verdade, é livre a quantidade de árbitros prevista pela cláusula arbitral, e as partes podem inclusive estipulá-lo em número par, se assim entenderem. Quando for o caso de um árbitro apenas, devem as partes escolhê-lo em conjunto. Nos casos de painel com mais de um árbitro, geralmente cada parte indica um (JARVIN, 2004, p. 20).

Hoje em dia, há um número cada vez maior de contratos internacionais com três ou mais partes contendo cláusula arbitral. Nessas avenças multilaterais, é frequente a previsão de painel com mais de um árbitro. Em tal caso, uma das partes deve escolher, sozinha, um desses árbitros, enquanto o outro polo da relação, composto por mais de uma parte, deve eleger o outro árbitro conjuntamente, o que nem sempre é possível. Esse assunto não é disciplinado pelo $F A A$, constituindo uma das mais significativas lacunas desse diploma legal.

Quanto à condição pessoal do árbitro indicado, o artigo $8^{\circ}$, § $2^{\circ}$ do $F A A$ expressamente prevê que "[t]ambém uma pessoa que não seja cidadã finlandesa pode atuar como árbitro na Finlândia”"13. A nacionalidade, de uma maneira geral, não pode servir de óbice à escolha do árbitro. Ela pode se tornar um problema, entretanto, se um dos árbitros escolhidos (seja ele o único ou o presidente do tribunal arbitral) possuir a mesma nacionalidade de uma das partes envolvidas na arbitragem, mas não da outra. Mais uma vez, o $F A A$ silencia sobre o assunto.

$\mathrm{O}$ artigo 9ำ $\S 1^{\circ}$ do $F A A$ exige que o árbitro seja independente, muito embora não defina o que seja essa independência. Seu conceito pode ser deduzido apenas das limitações e impedimentos à escolha do árbitro com base em sua independência. O FAA também obriga que o árbitro seja imparcial. Distingue-se a independência da imparcialidade na medida em que esta última possui uma natureza mais subjetiva ${ }^{14}$.

${ }^{13}$ Tradução livre para o Português do original em Inglês "Also a person who is not a Finnish citizen may act as an arbitrator in Finland". 
O artigo $9^{\circ}$ do $F A A$ também prevê que os árbitros eleitos assinem uma declaração de independência, revelando às partes "quaisquer circunstâncias" que possam macular sua independência ou sua imparcialidade. Mas não se exige que um árbitro possua, necessariamente, formação ou experiência no campo jurídico.

A exemplo do que sucede com a lei brasileira ${ }^{15}$, na Finlândia a parte pode apresentar arguição de recusa à indicação de um árbitro, desde que este "seja desqualificado para julgar a matéria, ou se existirem circunstâncias que façam surgir fundadas dúvidas quanto a sua imparcialidade ou independência"16, nos termos do artigo $10^{\circ}$.

Além disso, a substituição de um árbitro pode se dar, inclusive, quando ausentes as circunstâncias previstas pelo supramencionado artigo. A parte pode provocar a jurisdição regular para fins de destituição de árbitro que não responda a correspondências, se recuse a comparecer a audiências, ou cuja posição ou conduta seja incompatível com o ofício de árbitro. (JARVIN, 2004, p. 31).

\subsection{O Procedimento Arbitral}

O princípio maior a ser observado na organização do procedimento arbitral na Finlândia é a autonomia das partes. Isso fica expresso no artigo 23 do FAA, que faz referência a esse postulado. Há, no entanto, algumas regras que, por serem de observância obrigatória, excepcionam esse princípio. Exemplo é a do audiatur et altera pars, insculpido no artigo 22 do FAA (ESKO, 2004, p. 35), o qual determina que o tribunal arbitral conceda às partes oportunidade suficiente para alegar o seu direito.

Ao contrário da lei brasileira, o $F A A$, na parte dedicada ao procedimento arbitral, não prescreve qualquer tentativa de conciliação das partes a ser promovida pelo tribunal arbitral antes do início dos trabalhos propriamente ditos. A Lei no 9.307/1996, na esteira das reformas processuais havidas em nosso país no limiar do século passado (ALVIM, 2007, p. 137), previu a tentativa de conciliação tanto pelo juiz de direito, ainda na fase da instituição (judicial)

${ }^{14}$ A Lei $n^{\circ}$ 9.307/1996 estipula um rol mais extenso de predicados para os árbitros. O artigo 13, § 60 reza: "No desempenho de sua função, o árbitro deverá proceder com imparcialidade, independência, competência, diligência e discrição". (grifo nosso).

${ }^{15}$ Artigos 14 e 15 da Lei no 9.307/1996.

${ }^{16}$ Tradução livre para o Português do original em Inglês "if he would have been disqualified to handle the matter as a judge, or if circumstances exist that give rise to justifiable doubts as to his impartiality or independence". 
da arbitragem, como quanto pelo árbitro ou tribunal arbitral, no início do procedimento, a teor de seus artigos $7^{\circ}$, $\S 2^{\circ} ; 21$, $\S 4^{\circ}$; e $28^{17}$.

É de se notar a referência à celeridade do processo feita pelo artigo 23 , e desenvolvida por disposições como a do artigo 25 , que dá ao árbitro a possibilidade de fixar um período de tempo para que a parte que requisitou a arbitragem especifique as provas que pretende produzir, bem assim para que a parte provocada elabore a sua defesa.

$\mathrm{O}$ artigo 12 do $F A A$ exige que a parte interessada em recorrer à arbitragem notifique, por escrito, a outra parte. Essa notificação deve se remeter à convenção arbitral e conter a controvérsia a ser submetida à arbitragem.

O início do procedimento arbitral faz exsurgir litispendência sobre a matéria, impedindo que a mesma seja objeto de nova arbitragem, à maneira do que sucede na jurisdição regular.

A escolha do foro da arbitragem possui importantes implicações jurídicas. Por exemplo, as regras que regularão o procedimento arbitral serão aquelas do país-sede da arbitragem ${ }^{18}$ - a menos que as partes hajam disposto em contrário. A lei finlandesa não pressupõe qualquer conexão legal ou material entre a escolha do foro e a questão submetida à arbitragem, sendo livre a escolha das partes. Contudo, se a arbitragem é do tipo institucional, ou seja, submetida a uma certa instituição (como, por exemplo, o Keskuskauppakamarin välityslautakunta, original em finlandês para Instituto de Arbitragem da Câmara Central de Comércio da Finlândia), obviamente o foro será o dessa instituição.

Normalmente, são duas as fases do procedimento arbitral: a) a troca de alegações por escrito, pelas partes; e b) as audiências orais, que são sucedidas pelo laudo arbitral. Antes da primeira fase, é costume haver um encontro preliminar entre os árbitros e as partes. Por fim, dependendo da arbitragem, pode ser facultada às partes a apresentação de razões finais antes da lavratura do laudo.

\footnotetext{
${ }^{17}$ Eis o teor dos artigos citados: "Art. 7o $[. ..] \S 2^{\circ}$ Comparecendo as partes à audiência, o juiz tentará, previamente, a conciliação acerca do litígio. Não obtendo sucesso, tentará o juiz conduzir às partes à celebração, de comum acordo, do compromisso arbitral”. "Art. 21. [...] § 4 Competirá ao árbitro ou ao tribunal arbitral, no início do procedimento, tentar a conciliação das partes, aplicando-se, no que couber, o art. 28 desta Lei”. "Art. 28. Se, no decurso da arbitragem, as partes chegarem a um acordo quanto ao litígio, o árbitro ou o tribunal arbitral poderá, a pedido das partes, declarar tal fato mediante sentença arbitral, que conterá os requisitos do art. 26 desta Lei”. ${ }^{18}$ Conforme o artigo $1^{\circ}$ do $F A A$.
} 


\subsection{O Laudo Arbitral}

Os artigos 31 a 39 do $F A A$ regulam o laudo $\operatorname{arbitral}^{19}$ na Finlândia. Tais dispositivos são claramente inspirados nos artigos 28 a 33 da Lei-Modelo da UNCITRAL. Além do laudo arbitral, o tribunal ou o árbitro poderá emitir, em resumo, três outros tipos de decisão: os provimentos em separado, os provimentos de consentimento e os provimentos adicionais (SAVOLA, 2004, p. 48) ${ }^{20}$.

Os provimentos em separado podem ser de dois tipos. Em um caso no qual vários pedidos tenham sido formulados, os árbitros podem exarar um provimento em separado para decidir um deles, bem assim para decidir aqueles que não tenham sido contestados pela parte provocada.

Além disso, o provimento em separado serve para analisar questão prejudicial às demais. Por exemplo, em um caso envolvendo perdas e danos os árbitros podem decidir primeiro se há o direito às perdas e danos, para só posteriormente quantificá-los.

Os provimentos de consentimento têm lugar quando as partes chegam a um acordo no curso do processo e os árbitros o homologam mediante termo próprio. A recusa dos árbitros a uma tal homologação só será possível se o acordo representar infringência a normas de ordem pública.

Por fim, o provimento adicional se faz necessário quando o laudo arbitral possui lacunas. Ele se assemelha, assim, a uma decisão judicial que julga Embargos de Declaração opostos pela parte interessada.

$\mathrm{O}$ artigo 31 do $F A A$ prevê que as partes disponham acerca da lei aplicável ao mérito da causa. Nos modernos contratos comerciais internacionais, essa estipulação já vem contida em seu corpo. A indicação vincula os árbitros, que não podem basear o laudo em lei nacional de país diverso daquele que foi escolhido pelas partes.

Ao contrário da regra consagrada pela Lei-Modelo da UNCITRAL, na Finlândia o veredito dos árbitros não se sujeita ao voto da maioria: no caso de cada um dos três árbitros chegar a uma conclusão diferente, prevalecerá o voto do presidente do colegiado ${ }^{21}$. A lei brasileira vai no mesmo sentido: sendo três os árbitros, e se cada um deles votar num sentido (um pela procedência e outro, pela improcedência) e o presidente der pela procedência parcial, prevalecerá o seu voto (ALVIM, 2007, p. 149) ${ }^{22}$.

\footnotetext{
${ }^{19}$ No original em inglês, arbitral award.

${ }^{20}$ No original em inglês, separate awards, consent awards e additional awards.

${ }^{21}$ Artigo 32 do $F A A$.
} 
No aspecto formal, o laudo arbitral deve ser por escrito e assinado por todos os árbitros. É absolutamente dispensável a realização de uma sessão unicamente para a leitura do laudo arbitral, por importar em gastos adicionais para as partes envolvidas.

Quanto a seus efeitos, o laudo arbitral, assim que apresentado: a) faz res judicata ${ }^{23}$; b) torna-se exequível, não ser que seja puramente declaratório; c) determina a contagem de prazo para seu afastamento por jurisdição regular; e d) faz terminar o mandato dos árbitros.

Os honorários a que fazem jus os árbitros são fixados levando-se em conta o tempo exigido para a solução do conflito, a complexidade da matéria e outras circunstâncias de relevo ${ }^{24}$. As partes podem, inclusive, acordar o rateio proporcional das custas processuais e outras despesas.

\subsection{A Execução do Laudo Arbitral}

Uma das vantagens mais evidentes da escolha da arbitragem como meio de solução de conflitos é a impossibilidade de revisão judicial do mérito do laudo arbitral (TAIVALKOSKI, 2004, p. 65).

Como visto na Introdução, a lei finlandesa não faz distinção entre arbitragem doméstica e internacional. Também as arbitragens conduzidas em território finlandês não são discriminadas por conterem partes finlandesas ou alienígenas, ou mesmo por serem conduzidas por árbitros nacionais da Finlândia ou de outros países. Mas o $F A A$ somente prevê recursos em face de laudos arbitrais proferidos em território finlandês, e não no estrangeiro. $O$ modo de execução dos laudos também apresenta pequenas diferenças, a depender do país onde foram exarados.

No caso de ser o laudo arbitral considerado nulo, em tese não é exigida qualquer conduta das partes: a nulidade deve ser conhecida ex officio pelo juízo competente. É nulo o laudo arbitral: a) se o tribunal arbitral houver decidido questão não-arbitrável à luz da lei finlandesa; b) se o laudo conflitar com a ordem pública nacional finlandesa; c) se houver, no laudo, obscuridade ou incompletude suficiente para não tornar clara de que maneira a controvérsia

${ }^{22} \mathrm{O}$ art. $24, \S 1^{\circ}$ da Lei $\mathrm{n}^{\circ}$ 9.307/1996 expressamente prevê que " $[s]$ não houver acordo majoritário, prevalecerá o voto do presidente do tribunal arbitraP”.

${ }^{23} \mathrm{~A}$ Korkein oikeus, Suprema Corte finlandesa, decidiu que não se aplica ao laudo arbitral o artigo 31 do Código de Processo Civil daquele país, o qual prevê as hipóteses nas quais uma sentença judicial poderia ser anulada ou declarada nula. (SAVOLA, 2004, p. 60).

${ }^{24}$ Artigos 46 e 47 do FAA. 
foi decidida; e d) se o laudo não for por escrito ou não tiver sido assinado por todos os árbitros.

O laudo arbitral pode, ainda, ser afastado por decisão judicial, desde que haja provocação da parte interessada em até três meses da intimação, se: a) o tribunal arbitral tiver excedido sua autoridade; b) um árbitro não tiver sido regularmente designado; c) um árbitro tiver sido impugnado a tempo pela parte interessada e essa impugnação não houver sido aceita antes da lavratura do laudo arbitral; e d) o tribunal arbitral não tiver concedido à parte oportunidade suficiente para alegar o seu direito.

Há ainda, no direito finlandês, a figura da remissão, pela qual o juízo regular, ao ser provocado a declarar a nulidade ou o afastamento de um laudo arbitral, pode conceder ao tribunal arbitral oportunidade para tomar as providências necessárias à eliminação das causas que levaram ao requerimento de nulidade ou afastamento. A remissão está prevista no artigo 42 do $F A A$.

A execução do laudo arbitral, normalmente, se dá no foro de domicílio da parte vencida ou no de seus bens. Antes que o laudo seja declarado exequível pelo juízo, deve ser oportunizada a essa parte a chance de oferecer defesa escrita. Para laudos arbitrais exarados no exterior, o procedimento é idêntico ao das sentenças em território finlandês.

A única hipótese em que um juízo regular pode recusar-se a executar laudo arbitral estrangeiro ex officio é o reconhecimento de que esse provimento ofende a ordem pública nacional finlandesa ${ }^{25}$. A recusa pode ser limitada apenas à parte do laudo considerada ofensiva. No direito brasileiro, o Superior Tribunal de Justiça pode denegar a homologação para o reconhecimento ou execução da sentença arbitral estrangeira em dois casos, a teor do artigo 39 da Lei $\mathrm{n}^{0}$ 9.307/1996: quando o objeto do litígio não seja arbitrável ou quando a decisão nela contida ofenda a ordem pública nacional.

Já por provocação da parte, o laudo arbitral alienígena pode ter a execução recusada se a parte interessada provar: a) que não teve capacidade para celebrar a convenção arbitral; b) que não foi regularmente notificada da designação do árbitro; c) que o tribunal arbitral excedeu sua autoridade; d) que a composição do tribunal não respeitou o acordo entre as partes; ou e) que o laudo arbitral ainda não se tornou vinculante entre as partes ${ }^{26}$. Entre nós, o rol é mais extenso, nos termos dos seis incisos do artigo 38 da Lei $\mathrm{n}^{\circ}$ 9.307/1996, in verbis:

\footnotetext{
${ }^{25}$ Artigo 52, § 20 do FAA.

${ }^{26}$ Idem, artigo 53.
} 
Art. 38. Somente poderá ser negada a homologação para o reconhecimento ou execução de sentença arbitral estrangeira, quando o réu demonstrar que:

I - as partes na convenção de arbitragem eram incapazes;

II - a convenção de arbitragem não era válida segundo a lei à qual as partes a submeteram, ou, na falta de indicação, em virtude da lei do país onde a sentença arbitral foi proferida;

III - não foi notificado da designação do árbitro ou do procedimento de arbitragem, ou tenha sido violado o princípio do contraditório, impossibilitando a ampla defesa;

IV - a sentença arbitral foi proferida fora dos limites da convenção de arbitragem, e não foi possível separar a parte excedente daquela submetida à arbitragem;

$\mathrm{V}$ - a instituição da arbitragem não está de acordo com o compromisso arbitral ou cláusula compromissória;

VI - a sentença arbitral não se tenha, ainda, tornado obrigatória para as partes, tenha sido anulada, ou, ainda, tenha sido suspensa por órgão judicial do país onde a sentença arbitral for prolatada.

\section{A ARBITRAGEM KABEL}

\subsection{Introdução}

Em 14 de junho de 2006, com a indicação e aceitação do terceiro e último integrante do tribunal arbitral, foi instituído o processo arbitral entre PKC Group Oyj, empresa pública por cotas de responsabilidade limitada sediada em Kempele, Finlândia - de agora em diante denominada também Demandante -, e Kabel Indústria e Comércio de Chicotes Elétricos Ltda., sociedade limitada com sede na cidade de Almirante Tamandaré, Brasil - doravante referida também por Demandada.

A arbitragem que se seguiu foi uma das mais significativas em solo finlandês envolvendo empresa brasileira, razão pela qual se revela utilíssima para ilustrar, concretamente, a aplicação dos regramentos desse instituto referidos na primeira parte do artigo - registre-se que o processo arbitral seguiu o rito do $F A A$, tendo como aplicável, no mérito, a lei brasileira.

Passemos, assim, ao resumo fático da demanda.

\subsection{Resumo dos Fatos}

Em 26 de fevereiro de 1997, a Demandante incorporou PK Cables do Brasil Indústria e Comércio Ltda., sociedade limitada com sede no Brasil que veio a se tornar sua primeira filial fora de território finlandês. No intuito de acumular experiência na cultura de negócios em nosso país e de habituar-se aos usos locais no comércio, a Demandante considerou a possibilidade de ter uma empresa brasileira como sócia quotista na empresa recém-incorporada.

Em vista disso, no dia 14 de novembro de 1997, a Demandante firmou com 
a Demandada acordo de quotistas relativo à direção e administração da empresa incorporada. Nos termos desse acordo, a Demandante reservou-se $90 \%$ das quotas da empresa incorporada, ficando a Demandada com $10 \%$. Na prática, a Demandante permaneceu responsável pela administração da empresa. Também ficou assentado que, ao final do período de cooperação, a Demandante teria o direito de adquirir as quotas pertencentes à Demandada, assumindo a empresa por si só.

Em face de uma operação de aporte de capital da qual a Demandada recusouse a participar, a proporção de quotas foi posteriormente alterada para $96,83 \%$ e $3,17 \%$, respectivamente.

Nos anos que se seguiram ao acordo de quotistas, a Demandante passou a negociar com a Demandada a aquisição das quotas ainda em poder desta última, bem assim a revogação da cláusula de não-concorrência contida naquele instrumento. Não se chegando a um consenso sobre o preço das quotas de propriedade da Demandada, a Demandante remeteu àquela, em 16 de agosto de 2005, uma notificação de encerramento do acordo de quotistas, a qual, no seu entender, deveria produzir efeitos a partir do 31ํ dia após seu efetivo recebimento pela Demandada, o que ocorreu em 22 de agosto de 2005. Em consequência disso, a juízo da Demandante, sua retirada do acordo valeria a partir de 23 de setembro de 2005.

Mesmo após ter acusado o recebimento, a Demandada declarou não aceitar o término unilateral do acordo e que, por conta disso, continuava a considerá-lo válido para todos os efeitos. É que, no seu entender, a retirada da Demandante do acordo de quotistas não implicaria no término deste. $\mathrm{O}$ argumento utilizado foi o de que, à luz do direito brasileiro, a exclusão de uma parte sem justa causa somente poderia ser validamente declarada por um tribunal judicial.

Segundo o mesmo raciocínio, não haveria de se falar em venda das quotas restantes à Demandante. De acordo com a Demandada, o artigo 9.3 do acordo de quotistas não prescrevia a obrigação de venda das quotas remanescentes. Ademais, não se conceberia que a Demandada se visse forçada a transferir as quotas contra sua vontade.

Além disso, a Demandada declarou que continuou a ser tratada como sócia pela Demandante e que havia inclusive sido convidada a tomar assento em todas as assembleias da PK Cables do Brasil Indústria e Comércio Ltda. realizadas desde então. Esse fato demonstraria que até a Demandante ainda consideraria a Demandada como sócia na empresa incorporada, mesmo após o recebimento da notificação de encerramento do acordo de quotistas.

A Demandada também reconheceu a arbitrabilidade da questão submetida 
ao tribunal arbitral, porém condicionou esse reconhecimento à permanência em vigor do acordo de quotistas, uma vez que, se assim não fosse, estaria despida de qualquer força vinculante a cláusula arbitral contida no artigo 15 daquele acordo.

Por fim, quanto à cláusula de não-concorrência, considerou a Demandada que essa obrigação não poderia ser unilateralmente rescindida pela Demandante, e teria de ser por esta respeitada até mesmo após sua retirada do acordo de quotistas - no limite, inclusive se o tribunal arbitral viesse a entender pela transferência compulsória à Demandante das quotas ainda em poder da Demandada.

Com base nesse comportamento da Demandada, a Demandante se viu forçada a invocar o artigo 15 do acordo de quotistas, cláusula arbitral (equivalente à nossa cláusula compromissória) a teor dos artigos 2 a 6 e 12 do $F A A$, dando assim início ao processo arbitral.

\subsection{Processo Arbitral}

Perante o tribunal arbitral, a Demandante formulou os seguintes pedidos:

1) A confirmação da retirada da Demandante do acordo de quotistas a partir de 23 de setembro de 2005, mediante notificação da Demandada nos termos dos artigos 9.2 e 9.3 daquele acordo;

2) A declaração de que a propriedade de todas as quotas restantes em poder da Demandada fosse transferida para a Demandante mediante o pagamento de preço em consonância com o artigo 9.3 do acordo de quotistas;

3) A confirmação de que o preço de aquisição das quotas remanescentes em poder da Demandada, nos termos do artigo 9.3 acima citado, fosse aquele apurado por empresa de consultoria financeira contratada pela Demandante; ou, alternativamente,

A determinação do correto preço de aquisição das quotas restantes em poder da Demandada, nos termos do multicitado artigo 9.3 do acordo de quotistas;

4) A declaração de que a cláusula de não-concorrência do acordo de quotistas não mais subsistia, em face da cessação de vigência do acordo;

5) A condenação da Demandada ao pagamento dos honorários dos árbitros e de todas as custas do processo arbitral; e

6) A condenação da Demandada ao pagamento das despesas legais da Demandante no prazo de um mês a partir da prolação do laudo arbitral. Em caso de mora, que fosse aplicado o disposto no artigo 406 do Código Civil brasileiro ${ }^{27}$.

Em sua resposta, a Demandada rechaçou todos os pedidos da Demandante, e formulou os seguintes: 
1) A determinação de que o acordo de quotistas não poderia ser unilateralmente rescindido ou modificado;

2) A determinação de que o tribunal arbitral somente poderia julgar questões que houvessem sido negociadas de boa-fé, o que não incluiria a obrigação da Demandada de transferir suas quotas;

3) A determinação de que o tribunal arbitral não poderia excluir a Demandada do status de sócia quotista da empresa incorporada, PK Cables do Brasil Indústria e Comércio Ltda., sem justa causa;

4) A determinação de que a Demandante não poderia decidir a respeito das quotas de propriedade da Demandada;

5) No caso de o tribunal vir a decidir pela transferência das quotas da Demandada, a data da cessão deveria ser considerada como sendo o dia do efetivo pagamento do preço de aquisição;

6) A determinação de que o preço de aquisição das quotas fosse aquele apurado por empresa de consultoria financeira contratada pela Demandada;

7) A determinação de que a cláusula de não-concorrência ainda está em pleno vigor, e que essa obrigação deveria ser respeitada pela Demandante por cinco anos contados a partir de sua retirada do acordo de quotistas;

8) A condenação da Demandante em todas as custas processuais, incluídos gastos legais, honorários arbitrais e demais despesas.

\subsection{Laudo Arbitral}

\subsubsection{Arbitrabilidade do caso, lei aplicável, língua do processo e foro da arbitragem}

Decidindo o caso, o tribunal arbitral analisou, a título preliminar, a questão de sua arbitrabilidade, à luz do artigo 15 do acordo de quotistas, o qual dispunha que qualquer disputa ou controvérsia oriunda desse acordo ou a ele relativa deveria ser resolvida por arbitragem, segundo o rito do Finnish Arbitration Act. $\mathrm{O}$ artigo em tela também prescrevia que o tribunal arbitral deveria ser composto por 03 (três) árbitros, um escolhido por cada parte, e o terceiro indicado em conjunto como presidente do colegiado - ou, inexistindo consenso, designado pelo Comitê de Arbitragem da Câmara Central de Comércio da Finlândia (Keskuskauppakamarin välityslautakunta).

${ }^{27}$ Eis o seu teor: "Art. 406. Quando os juros moratórios não forem convencionados, ou o forem sem taxa estipulada, ou quando provierem de determinação da lei, serão fixados segundo a taxa que estiver em vigor para a mora do pagamento de impostos devidos à Fazenda Nacional.” 
O tribunal arbitral analisou as alegações da Demandada, para quem a arbitrabilidade da questão estaria condicionada à permanência em vigor do acordo de quotistas, e rechaçou esse entendimento. $\mathrm{O}$ tribunal resolveu a controvérsia à luz do $F A A$, que reproduz a solução dada pela legislação arbitral da maioria dos países: a validade de um contrato não afeta a da cláusula arbitral nele contida princípio entre nós conhecido como o da autonomia da cláusula compromissória. Com base nisso, o tribunal arbitral declarou sua jurisdição para decidir todos os pedidos submetidos pelas partes em suas manifestações no processo.

Considerando o teor do artigo 13 do acordo de quotistas, o tribunal determinou que a lei aplicável ao processo seria a brasileira, em obediência ao artigo 31 do FAA. Decidiu-se ainda, por força dos artigos 11 e 15 do acordo, que o inglês seria a língua oficial do processo. Por fim, também de acordo com o artigo 15, a cidade de Helsinki, Finlândia foi escolhida como foro da arbitragem, sob o rito previsto pelo Finnish Arbitration Act.

\subsubsection{Encerramento do acordo de quotistas}

A partir das provas apresentadas no curso do processo, o tribunal arbitral concluiu que, ao contrário do alegado pela Demandada, as partes efetivamente negociaram por vários anos - ainda que sem sucesso - o preço de venda das quotas em poder da Demandada e a modificação da cláusula de não-concorrência contida no acordo de quotistas. Essa constatação invalidaria, por completo, a alegação de que a Demandante teria infringido o artigo 14 do acordo, o qual dispunha que as partes deveriam fazer todo o possível para dirimir, por meio da negociação, as disputas eventualmente existentes. $O$ tribunal subsidiou seu entendimento em outro comando do mesmo artigo 14, o qual rezava que se a resolução dessas disputas pela negociação não fosse possível, deveriam elas ser resolvidas por meio da arbitragem. Se a Demandada recusou-se a vender suas quotas após receber a notificação de encerramento expedida pela Demandante em 16 de agosto de 2005, a invocação da arbitragem seria, assim, uma consequência natural.

Demais disso, o tribunal arbitral - muito embora haja feito ressalvas à pouca tecnicidade da linguagem jurídica utilizada na notificação - considerou a intenção da Demandante de efetivamente encerrar, por meio da notificação, a cooperação que mantinha com a Demandada. Consoante o artigo 9.2.1 do acordo de quotistas, qualquer das partes teria o direito de retirar-se a qualquer tempo após 07 (sete) anos a partir da data de constituição da empresa incorporada, PK Cables do Brasil Indústria e Comércio Ltda., o que, a sentir do tribunal arbitral, autorizaria a saída da Demandante do contrato sem que houvesse prévia negociação. Como esse prazo de 07 (sete) anos foi completado em 15 de novembro 
de 2004, a Demandada teria simplesmente feito uso dessa previsão contratual, e não rescindido unilateralmente o instrumento, como quis a Demandada.

Finalmente, dispôs o tribunal arbitral que a Demandada infringiu o artigo 9.3 do acordo de quotistas, o qual continha a previsão da venda compulsória das quotas remanescentes a "preço de mercado". Uma vez que a Demandada recusou-se a vendê-las, a Demandante, a seu turno, não concordou em negociar seu preço de mercado. Entendeu o tribunal que, muito embora o artigo 18 do acordo previsse sua duração até que ambas as partes detivessem quotas da $\mathrm{PK}$ Cables do Brasil Indústria e Comércio Ltda., isso não conferiria à Demandada a faculdade de, unilateralmente, impedir o término desse instrumento. $\mathrm{O}$ mero fato de que a Demandante continuou a convidar a Demandada para todas as assembleias da empresa incorporada não implicaria no seu reconhecimento de que o acordo de quotistas ainda estivesse vigente.

Dessa forma, o tribunal arbitral considerou o acordo de quotistas encerrado em 23 de setembro de 2005, trigésimo primeiro dia após o recebimento, pela Demandada, da notificação expedida pela Demandante em 16 de agosto de 2005.

\subsubsection{Preço das quotas da Demandada}

Nos termos do artigo 9.3 do acordo de quotistas, o preço de aquisição das quotas da empresa incorporada deveria ser o de mercado. Dado que a PK Cables do Brasil Indústria e Comércio Ltda. não possuía ações negociadas na bolsa, esse preço deveria ser alcançado por avaliação equitativa procedida pelo próprio tribunal arbitral.

À luz dos laudos apresentados por ambas as partes, o tribunal estabeleceu o preço devido pelas quotas ainda em poder da Demandada. $O$ valor alcançado foi $62,57 \%$ superior ao proposto pela Demandante, e 65,47\% inferior àquele considerado justo pela Demandada.

\subsubsection{Determinação de transferência das quotas da Demandada à Demandante}

O tribunal também determinou que a Demandada transferisse as quotas em seu poder à Demandante imediatamente após o recebimento do preço estabelecido, ou após a notificação de seu depósito, seja em juízo, seja perante instituição bancária brasileira.

\subsubsection{Validade da cláusula de não-concorrência}

$\mathrm{O}$ artigo $8^{\circ}$ do acordo de quotistas regulava a cláusula de não-concorrência entre as partes, com a peculiaridade de que seu artigo 18, parágrafo segundo, previa a vigência dessa obrigação mesmo após o encerramento do acordo. Em 
que pese o teor dos dispositivos mencionados, a Demandante requereu ao tribunal arbitral a declaração de término de vigência dessa cláusula na data em que a Demandada acusou ter recebido a notificação de encerramento do acordo. Para subsidiar esse posicionamento, trouxe à baila Comunicação da Comissão Europeia relativa à remessa de casos de concentrações (2005/C 56/02), de 05 de março de $2005^{28}$. Sucessivamente, a Demandante requereu a consideração do período de 05 (cinco) anos previsto pela lei brasileira, tendo-se como termo a quo a data de assinatura do acordo, 14 de novembro de 1997.

A Demandada anuiu com o estabelecimento do período de 05 (cinco) anos, mas entendeu que o início de sua fluência deveria ser a data do pagamento das quotas em seu poder.

O tribunal arbitral entendeu que não se cogita da aplicação do direito comunitário europeu ao caso, como quis a Demandante, uma vez que a lei aplicável à resolução da controvérsia é a brasileira. Decidiu-se, assim, pela aplicação do período de 05 (cinco) anos, com termo a quo no trigésimo primeiro dia após a data de recebimento, pela Demandada, da notificação de encerramento, ou seja, 23 de setembro de 2005. A cláusula de não-concorrência estaria em vigor, assim, até 23 de setembro de 2010.

\subsubsection{Custas processuais: despesas das partes e honorários arbitrais}

Para efeito de cálculo das custas processuais, o tribunal arbitral considerou os relatórios de despesas apresentados por cada uma das partes, além da quantia referente aos honorários e despesas dos árbitros (os quais haviam sido adiantados no início do processo, em cotas iguais, por ambas as partes).

Em face do resultado da disputa, o tribunal arbitral proclamou a Demandante sucumbente à razão de $1 / 3$ (um terço) das custas processuais, e a Demandada à razão de $2 / 3$ (dois terços), devendo esta efetuar o pagamento da diferença havida no prazo de 30 (trinta) dias contados a partir da lavratura do laudo arbitral. Determinou-se ainda que, no caso de mora, os juros incidentes deveriam ser aqueles estipulados pelo artigo 406 do Código Civil brasileiro. O mesmo dispositivo legal se aplicaria à eventual mora verificada na transferência das quotas sociais da Demandada à Demandante.

${ }^{28}$ JORNAL OFICIAL DA UNIÃO EUROPEIA. Bruxelas, 5 Mar. 2005. Disponível em http://eur-lex.europa.eu/JOHtml.do?uri=OJ\%3AC\%3A2005\%3A056\%3ASOM\%3AP T\%3AHTML. Acesso em: 13 dez 2010. 


\subsubsection{Apelação do laudo arbitral}

Por fim, determinou o tribunal que as partes têm direito a apelar do laudo arbitral, unicamente quanto aos honorários e despesas dos árbitros, perante a Corte Distrital de Helsinki, Finlândia, no prazo de 60 (sessenta) dias a partir do recebimento, pela parte, de cópia original do laudo, em face da impossibilidade de revisão judicial do mérito do laudo arbitral.

\section{REFERÊNCIAS}

ALVIM, J. E. Carreira. Comentários à lei de arbitragem. 2. ed. Curitiba: Juruá, 2007. ESKO, Timo. The Arbitration Proceedings. In: SAVOLA, Mika (Ed.). Law and practice of arbitration in Finland. Helsinki: Finnish Arbitration Association, 2004.

FINLAND CENTRALCHAMBER OFCOMMERCE. Annual Report 2009. Helsinki, 2010. Disponível em: 〈http://www.keskuskauppakamari.fi/digijulkaisu/Vuosikertomus2009eng eDoc/KKK vuosikertomus2009 eng www.pdfs. Acesso em: 7 nov. 2010.

JARVIN, Sigvar. The Arbitral Tribunal. In: SAVOLA, Mika (Ed.). Law and practice of arbitration in Finland. Helsinki: Finnish Arbitration Association, 2004.

L.O. BAPTISTA ADVOGADOS. Arbitragem: Material de apoio. São Paulo: Ferrari Editora e Artes Gráficas, 2005.

MÖLLER, Gustaf. The Arbitration Agreement. In: SAVOLA, Mika (Ed.). Law and practice of arbitration in Finland. Helsinki: Finnish Arbitration Association, 2004.

SAVOLA, Mika (Ed.). Law and practice of arbitration in Finland. Helsinki: Finnish Arbitration Association, 2004.

SAVOLA, Mika. The Arbitral Award. In: SAVOLA, Mika (Ed.). Law and practice of arbitration in Finland. Helsinki: Finnish Arbitration Association, 2004.

TAIVALKOSKI, Petri. Enforcement of Arbitral Awards. In: SAVOLA, Mika (Ed.). Law and practice of arbitration in Finland. Helsinki: Finnish Arbitration Association, 2004.

Artigo recebido em 20/01/11 e aprovado para publicação em $05 / 12 / 11$

Como citar: CAVALCANTI, Felipe Dutra Gurgel. A arbitragem Kabel: um case brasileiro na Finlândia. Scientia Iuris, Londrina, v. 15, n. 2, p. 125-143, dez. 2011. DOI: 10.5433/2178-8189.2011v15n2p125 